\title{
Academic Development and Support Lessons from Council on Higher Education Audit Reports
}

\author{
Livingstone Makondo
}

\author{
Academic Development Practitioner, Centre for Excellence in Learning and Teaching (CELT) \\ Durban University of Technology, Midlands Centre, P.O. Box 101112, Pietermaritzburg 3209 \\ Email: livingstoneM@dut.ac.za or livingstonemakondo@gmail.com
}

\section{Doi:10.5901/mjss.2014.v5n11p29}

\begin{abstract}
The offering of academic development and support services to academics and students is on rise as universities battle to meet higher education transformation agenda. Special focus is here given on what the audit reports of the South African Higher Education Quality Committee of the Council on Higher Education established on the relationship between academic development and teaching and learning. Audit reports from five South African universities were randomly selected for this literature review paper. The centrality of academic development and support initiatives focusing on university teaching staff came to the fore. The need for educational practitioners to assume strategic roles in curriculum design, design of university teaching and learning agenda, induction and academic support, defining the relevant institutional scope of academic development, policy clarity and implementation, teaching excellence, structural and manpower constrains were foregrounded.
\end{abstract}

Keywords: Curriculum, Practitioners, University, Teaching, Learning, Assessment

\section{Introduction}

Higher education (HE) context is in constant flux world over due to forces of globalisation and massification of HE among others. In South Africa, the spirit of change has been echoed in the vision of the White Paper 3: A programme for the transformation of HE that advocates for a single and coordinated HE system. Furthermore, the Council on Higher Education (CHE) is assigned by the Higher Education Act of 1997 the responsibility for quality assurance in HE in South Africa. This saw the first audit cycle that was done between 2004-2009 focusing on 'institutional arrangements for assuring quality in the core areas of teaching and learning, research and community engagement' (CHE 2004, p.4). The CHE went on to produce the criteria for institutional audits (CHE 2014a) and HEQC institutional audits manual (CHE 2007).

The HE Teaching and Learning Agenda (TLA) discourse builds on the White Paper 3.1.27.9 that spells out,

the need to produce graduates with the skills and competencies that build the foundations for lifelong learning, including, critical, analytical, problem-solving and communication skills, as well as the ability to deal with change and diversity, in particular, the tolerance of different views and ideas.

This suggests that properly designed University curriculum should produce students who are equipped with abilities and skills to engage in complex higher order thinking. Higher order thinking, as Resnick (1987) puts it, involves nuanced judgement, interpretation and it is an effortful process which demands self-regulation from the student.

Also, the resultant learning and teaching that should be facilitated at the University should give students the ability to 'crack the code', get 'intellectual power', through access to the concepts, theories and methods of enquiry and analysis generated within particular specialist discourses, and 'social power' (Northedge 2003), through membership of knowledge communities which may control decision making, professional practice and employment opportunities. In other words, a competent university student in the academic culture understands 'how argument and evidence [are] structured and presented in his/her discipline' (Starfield 1994, p.17). For these noble expectations to be achieved at the University, teaching staff need to design and use learning-teaching facilitation approaches that promote student engagement through student centeredness against the traditional popular knowledge transmission approaches. This speaks of the need to have academics assisted in the design of such approaches primarily by competent academic developers.

Moreover, the teaching and learning environment now suggests that neither traditional 'knowledge delivery' models of teaching, nor a purely 'student-centred' approach, adequately addresses the challenges of student diversity. Instead, Northedge (2003) proposes an emphasis on the sociocultural nature of learning and teaching, modelling learning as 
acquiring the capacity to participate in the discourses of an unfamiliar knowledge community and teaching as supporting that participation. In quintessence students need practice at participating both vicariously, as listeners and readers, and generatively, as speakers and writers, so that they can develop identities as members of the knowledge community and move from peripheral forums to more active, competent engagement with the community's central debates. This speaks to teaching as enabling participation in knowing (Wells \& Claxton 2002).

On the facilitative model of teaching and learning, 'teaching methods must conform to a transformative model of quality where academics take pains to grapple with the low level of subject mastery with which students enter HE, go down to their level and promote enterprise, student autonomy and enhance cooperation and consultative learning' (Mammon (2006, pp. 476, 639). Within this context, problem-based learning is an example of an active method that require students to question, to speculate, to generate solutions, to use the higher order cognitive activities. 'Good teaching' (Biggs 1999, p.58) then becomes getting most students to use the higher cognitive level processes that the more academic students use spontaneously and good teaching narrows the gap between surface and deep learning. This means the role of the teacher becomes that of 'discourse guide' (Mercer 1995) preoccupied with maximising on epistemological access. Maphosa \& Mudzielwana (2014), Ndebele (2014), Maphosa \& Wadesango (2014) and Makondo (2010) shed further valuable light on how professionalization of university teaching could be attained.

\section{Objectives}

This literature analysis paper sought to do two things namely, to:

i) Examine salient academic development and support concerns raised by the audit reports?

ii) Explore ways of redressing the salient academic development and support concerns raised by the audit report.

\section{Methodology}

This literature analysis paper drew its data from CHE audit reports on academic development and teaching and learning done for five South African universities by the South African Higher Education Quality Committee (HEQC). Close attention is paid to the CHE 2010, 2010a, 2011, 2011a and 2011b audit reports. The audit reports are a valuable source of data as they are a result of work done by the HEQC, a permanent sub-committee of the CHE. The randomly selected audit reports are for a technical university, predominantly distance learning and comprehensive universities. PDF files were downloaded from the $\mathrm{CHE}$ website and thematic analysis was done to examine the salient academic development and support features.

\section{Results and Discussion}

This section is devoted to presenting the findings from the five CHE audit reports and accompanying discussion. This section highlight areas that educational practitioners/academic advisors could do well if they focus on them as they enhance their execution of their roles toward the attainment of the university core business. The salient emergent themes are teaching and learning agenda development, curriculum design, induction and academic support, definition of scope of academic development and support, policy clarity and implementation, teaching excellence, structural constrains and manpower constrains among others.

\section{Teaching and Learning Agenda}

CHE audit report notes that 'during interviews with a range of staff members there was acknowledgement that in the absence of a clear academic project at the university (name withheld) and a coherent policy direction, most teaching and learning matters are attended to on an ad hoc or reactive basis' (CHE 2011a, p. 20). To ameliorate this sad reality, academic developers could play critical roles in promoting scholarly teaching and scholarship of learning and teaching (Maphosa \& Wadesango 2014). This calls for academic practitioners who explore pragmatic ways of promoting professional development of academics (Ndebele 2014) in a changed terrain that calls for mindset change which Makondo (2012) reckons to be prerequisite for academic excellence.

Furthermore, the role of educational practitioners in the design and implementation of policies underpinning the TLA of Universities has not been fully explored by many universities as shown by the audit reports under review. One CHE (2011, p. 17) audit report submits that 'Teaching and Learning Coordinators are considered to provide a valuable link between the Academic Planning Committee and the faculty executive. The Centre needs to receive all review reports 
as part of the normal flow of information at the University'. I submit that universities stand to have the structures of HoDs, programme coordinators, deans and the academic staff in general greatly helped in the design and review of teaching and learning related policies namely the: Work-integrated, Teaching and Learning, Assessment of Teaching and Learning, Peer Evaluation, Mentoring and E-Learning to name a few. This should be done through strategic involvement of all interested units of the university who are eventual implementers. Makondo \& Makondo (2014, pp. 301-309) explore this theme in their discussion of the interplay between South African higher education context and academic development. In addition, Makondo (2014, p. 179) argues for 'the need for educational practitioners to execute different agential roles meant to ensure that requisite enabling teaching and learning policies are in place and well popularized'. Also, the importance of efficient communication systems has been drawn attention to so that educational developers are kept abreast of internal and external expectations in respect of the disciplines that they offer assistance to. Among others, this ensures better preparation and delivery of enhanced academic development and support services.

Against this premise, the CHE (2011b) audit report observes lack of support for academics to professionalise their teaching' whilst 'efforts to change teaching and improve learning are essentially battles over institutional values, rewards, and behaviours' (Alderson, Wagener and Shamanism 2000, p.19). According to Taylor (2005), as academic communities' welcome greater diversity among students and faculty (lecturers), forms of scholarship and teaching and learning strategies, expectations of the $A D$ role are growing. Academic developers should strategically collaborate with their academic colleagues to build teaching and learning capacity not only among individual teachers, but also through curriculum development (Cook 2001), the integration of technology in teaching (Gandolfo 1998) and career development (Åkerlind \& Quinlan 2001). Increasingly, academic developers are called upon to provide leadership in problem solving and change at the institutional level (Diamond 2005).

Within the preceding context, Taylor (2005) argues that the processes of academic development (AD) and of leadership can be characterized through Palmer's (1998) processes of knowing, teaching and learning in community. Surmising from Palmer (1998), one notes that in AD, as in teaching, it is essential to know yourself, your discipline and your community. The second process critical to effective $A D$ is teaching in community which requires the expert to make connections among self, learners, the knowledge to be learned, and the context (Palmer 1998). Palmer's third process, learning in community, is a reciprocal process of recognizing opportunities to learn, forming partnerships, combining ideas, and building capacity for collaborative problem solving. Learning in community requires setting expectations for learning and facilitating the reflection, discussion and action necessary for learning.

According to Taylor (2005), it is clear that AD practitioners in Universities need to execute diverse leadership roles calculated to design, implement and oversee an enhanced the University TLA. Kouzes \& Posner (1995) contend that by exercising identity, integrity and growth in their teaching, AD developers demonstrate the credibility, fairness, honesty, connection, enthusiasm, genuineness, commitment, competency, sensitivity to values and hopes, broadmindedness and openness characteristic of effective leaders. Furthermore, according to Diamond (2005) AD practitioners should give strong emphasis on knowing in community of practice, reflect effective leadership when they listen, appreciate and use internal and external contexts, recognize problems and opportunities, consult, generate vision in harmony with community, are aware of established conventions, communicate effectively, align beliefs and action.

\section{Scope of Academic Development}

It clearly emerges that academic development and support (ADS) is understood differently in universities as testified by the examined audit reports. In terms of $A D$, the audit report submits that 'without an understanding of $A D$ as also being about staff and curriculum development it will be difficult for [the university] to move from the notion of the student as being solely responsible for his or her own success to the acknowledgement that institutional systems and curriculum approaches contribute strongly towards student retention and success' (CHE 2011a, p.23). Educational development practitioners should exercise their agency to ensure that an understanding of $A D$ prevalent within their institutions is akin to the White Paper 3.2.96 submits that,

Staff development, including academic development that is improved qualifications, professional development and career pathing, instructional (teaching) development, management skills, technological reskilling and appropriate organisational environment and support ought to be availed to academics.

Surmising from the White Paper one notes that $A D$ offerings would depend on the context of the involved institution. There is an open call for academics to improve upon their qualifications for them to be properly qualified to handle university teaching and learning, research and community issues. At the same time, staff development seeks to 
effect professional development and career pathing so that the universities could afford to retain satisfied academic staff (Makondo 2014). Acquiring of management skills seem to be usually neglected in the AD support initiatives yet it is pivotal for the academics' operations and educational practitioners should attend to it. Also, in line with the world of business expectations, academics who are technologically skilled will be in a possession to pass on the knowledge and abilities to their students. In short, one notes that educational developers ought to proactive so that they are qualified to execute diverse requisite functions expected from their portfolios.

\section{Curriculum Design}

Some CHE audit report saliently reckons that there is need to address through extensive training 'the curriculum development skills' of academic staff members which impact on the quality of documentation they design and submit to 'Institutional Committee on Academic Standards, the coherence of programmes and the quality of study guides' (CHE 2010). Similar sentiments came through audit report recommendation 17 that speaks of the need to, 'take the necessary steps to develop capacity and provide resources at school and departmental level in curriculum design and programme development' (CHE 2011b). This highlights the importance of educational practitioners being able to offer curriculum support so that academic staff could design programmes acquiescent with HEQC expectations. Within this context, curriculum development should be understood to encompass how a 'curriculum is planned, implemented and evaluated as well as what people, processes and procedures are involved (Ornstein \& Hunkins 2009, p.15). Drawing from Luckett $(1995, p .138)$, it is clear that far-reaching curriculum reform will require a change in our epistemological and pedagogical assumptions. The central agency for curriculum development lies with teaching staff, growth and change in learner understanding is the focus of the curriculum. Therefore, educational practitioners should draw on the expertise of academic developers on 'curriculum design and review, teaching, learning and assessment services' (Makondo 2014) to exercise strategic agency in the design, implementation and review of teaching and learning policies.

In terms of curriculum review approaches, O'Neill $(2010$, p.67) is handy for noting that there are different approaches used by educational developers in approaching curriculum revision. Some advocate for 'an ongoing dialogic approach with academic staff, including listening and in-depth questioning'. This approach entails trying at all cost to see curriculum issues through the eyes of the participant academic staff. For implementation, academic advisers have first to 'understand the drivers and other aspects of the context in order to be well placed to support the staff in revising their curricula' (O'Neill 2010, p.67). In the Archerian language the drivers might be conducive university culture and structure (Archer 2000, 2003). A related approach named 'internal consultant' (Land 2004, p.101) which calls for academic practitioners to familiarise themselves well with the concerned schools/faculties they would work with through spending much time listening and watching and saying very little. O'Neill $(2010, p .69)$ further argues that educational developers need to be supported through continuing professional education courses to develop communication, negotiation and curriculum development skills. This speaks to the pragmatic applicability to professionalization of academic development support initiatives of the Maphosa and Mudzielwana (2014, p.72) proposed professionalizing of teaching model. Their model is pertinent as it highlights, with reference to professionalization of teaching [academic development support initiatives], the need for teacher training programmes, short courses, research and publication/conferences, curriculum development among others.

\section{Policy Clarity and Implementation}

CHE (2010a, p.15) audit report states that there was '... minimal conceptual engagement with the pedagogy underpinning the idea of student-centredness...' In this context, the HEQC panel 'stress the importance of clear senior management leadership' on the processes of rethinking programmes in the context of the implementation of the Higher education qualification framework (HEQF). Cases in point are that at one university the Teaching and Learning Policy and Monitoring and Evaluation of Teaching and Learning Policy policies were due for review yet the 'structural and agential roles' (Makondo \& Makondo 2014) they advocated for had not yet been operationalized. This speaks to lack of culture of popularising policies to ensure compliance with defining teaching and learning tenets embedded in the policies. In terms of the culture of teaching and learning, universities need to improve upon some HEQC audit report that read;

Interviews with a range of academics indicated that at department level there is no awareness of either policy or of its implications for practice. It is clear to the Panel that the policies have not yet been implemented. The Panel is of the firm opinion that both policies can potentially contribute a great deal to improving the quality of teaching and learning at the University (CHE 2011b). 
These observations seem to highlight negation of adherence to quality and efforts towards professionalization of teaching and learning. This stands contrary to the national desire to improve on student success-here simply understood as 'getting students into and through college to a degree or certificate' (Ewell \& Wellman 2007, p.2). This status quo eventually has negative bearing on design and implementation of appropriate TLA hence the culture should be improved upon by a sustained positive culture advocated by staff in designated university structures.

On the other hand, lecturers at another university were reported to be getting 'training in areas including interpreting policies for teaching and assessment, OBE-related workshops on issues like level descriptors, writing interactive study guides, using the e-learning system, teaching large classes, setting multiple-choice questions and using technology effectively for presentations' (CHE 2010, p.18). Academic practitioners are therefore encouraged to realize that their scope of operation is wide and pivotal as shown by these three case audit reports. This calls upon academic practitioners to be conversant with teaching and learning policies so that they could offer relevant guidance and support to academics the majority of whom are not trained to teach (Makondo 2010).

\section{Induction and Academic Support}

The other salient observation from the audit report is that 'there is a rather superficial induction programme' (CHE 2011b). Induction that introduces university academics to what is expected of them in executing their key roles in teaching, learning, research and community engagement early is key before wrong habits and practices are fossilized. Making inferences from Maphosa and Mudzielwana (2014), these efforts goes a long way in professionalization of teaching in universities. One notes that induction ought to focus on 'deep' issues of university core business. Drawing from Coles (2002, p.8), ' ... professional development requires high levels of support and structure but as little direction as possible'. This suggests that the facilitators ought to do splendid induction job as they are giving new university lecturers requisite survival kits. This approach is premised against some remarks from 'interviewees that little is happening to support staff', and that often staff feel that they are 'thrown in at the deep end' (CHE 2011b) without sufficient preparation or support. And, the induction sessions should result in culmination of long professional symbiotic relationships among academics and educational practitioners and I strongly suggest that the later would do well to nurture it as s/he should have traversed the terrain and knows fully well what awaits the novice academic staff members.

\section{Structural Constrains}

Another salient feature that emerges from the CHE audlt report is call for institutions to work out a system that 'ensure a coherent institutional system of support for academics' (CHE 2011a p,23). In essence, lack of harmony among departments has resulted in failure to give academics requisite support as the Academic support units, the Quality Assurance Office, the Academic Planning Committee and the Teaching and Learning Committee at times spend a lot of their valuable energies in antagonistic matters. This is coupled, in other institutions by the fact that at times these offices have different reporting lines like some might be reporting to DVC Academic, DVC Quality or to the VC.

\section{Manpower Constrains}

Shortage of educational development practitioners emerge as a salient feature in audit reports under review. This trend has similarities with trends in the academics attraction and retention trends in the mainstream academic teaching sector (Makondo 2014) for reasons ranging from skills shortage and lack of proactive human resource attraction and retention skills among others. In addition, Ndebele (2014) is pertinent for having discussed at length the enabling and constraining conditions in the growth, development and roles of educational staff development facilitators. The bottom line then is that Academic Centres need be proactive and make do with available human and material resources. Valuable lessons could be drawn from CHE (2011, p.17) audit report of a Centre that 'achieve their mission with limited staff by devolving some of their work to faculties or working with student Affairs and residences. Provision of these services across all campuses remains a serious challenge faced by this unit. The need for more capacity to work with curriculum development has been approached innovatively through the use of curriculum officers from the faculties. This underscores the need for members of $A D$ who are not content to doing only the 'soft and easy things as was the norm' but calls for pragmatic, venturing practitioners prepared to 'burn candles' even late for the better of their profession.

Related to the preceding, 'there is no evidence that the provision of these workshops is sustainable in the long term [due to staff shortage or financial capital] or is sufficient to meet the development needs of academic staff' (CHE 2011b, p.35). Academic developers need be innovative by exploring diverse professional development practices. From 
Maphosa and Wadesango (2014, p.78), eight approaches are discussed within the context of scholarly teaching and the scholarship of learning and teaching which I submit applies to be academic development support initiatives. Succession policies need be clearly spelt out in the Centres so that core projects of the Centres should not be stalled due to staff turnover.

\section{Teaching Excellence}

Moreover, some HEQC audit interviewees pointed out that there is no 'sufficient focus on teaching and learning in the criteria for promotion' (CHE 2011b). This observation speaks to the need of a sustained teaching and learning culture that might be best attained through Awards systems. On this note, the audit report notes that the Institutional Teaching Excellence Award (named differently in many institutions) appears to be a good motivational tool with a reward structure that signifies genuine support for teaching excellence (CHE 2010, p.22). This also motivates academic staff to excell either in teaching facilitation or research or community engagement. Educational developers stand to achieve much in enhancing teaching and learning.

\section{Conclusion}

The importance of the CHE audit reports cannot be overemphasized. These reports help greatly by showing one where it all begun for one to appreciate the strides made in professionalizing ADS initiatives. The diverse pivotal roles to be executed by educational practitioners' calls for individuals who are well prepared to acquire requisite qualifications and experience for them to remain relevant in the flux higher education context. The university structures should appreciate that their institutions stand to be aided greatly in achieving their institution's core mandates by proactive and competent academic advisors. The need for curriculum design and teaching and learning policy design has been highlighted alongside the design of appropriate teaching and learning agenda, teaching excellence, induction and academic support. The dark sides of manpower and structural constrains has also been explored and redress recommendations have been made.

\section{Recommendations}

It is necessary to have a study that looks at how the concerned universities responded to the concerns raised by the audit reports this study examined.

\section{References}

Åkerlind, GS \& Quinlan, KM 2001, Strengthening collegiality to enhance teaching research and scholarly practice: An untapped resource for academic development. In Lieberman, D \& Wahlberg C (Eds.), To improve the academy, vol. 19, pp. 306-321.

Archer, M 2000, Being human: The problem of agency, Cambridge, UK: Cambridge University Press.

Archer, M 2003, Structure, agency and the internal conversation. Cambridge, UK: Cambridge University Press.

Biggs, J 1999, What the student does: Teaching for enhanced learning, Higher education research and development. vol.18, no.1, pp. $57-75$.

Coles, C 2002, Developing professional judgement, The Journal of continuing education in the health professions, 22, pp. 3-10.

Council on Higher Education, 2004, Higher Education Quality Committee Criteria for institutional audits.

Council on Higher Education, 2004a, Higher Education Quality Committee Institutional audit framework

Council on Higher Education, 2007, Higher Education Quality Committee institutional audits manual.

Council on Higher Education, 2011b, Audit report on the University of Venda. Report of the Higher Education Quality Committee to the University of Venda

Council on Higher Education, January 2010a, Audit report on the University of South Africa. Report of the Higher Education Quality Committee to the University of South Africa, HEQC Audit Report Number 24.

Council on Higher Education, July 2011, Audit report on Cape Peninsula University of Technology, Report of the Higher Education Quality Committee to the Cape Peninsula University of Technology', HEQC Audit Report Number 32.

Council on Higher Education, July 2011a, Audit report on University of Limpopo. Report of the Higher Education Quality Committee to the HEQC Audit Report Number 31.

Council on Higher Education, September 2010, Audit report on North-West University, Report of the Higher Education Quality Committee to the North-West University, HEQC Audit Report Number 27.

Diamond, RM 2005, The institutional change agency: The expanding role of academic support centers, In Chadwick-Blossey, S \& Robertson DR (Eds.), To improve the academy, vol. 23, pp. 24-37. Bolton, MA: Anker Publishing. 
Education White Paper 3, A Programme for Higher Education Transformation. Staatskoerant, 15 Augustus 1997 No.18207.

Ewell, P \& Wellman, J 2007, Enhancing Student Success in Education: Summary Report of the NPEC Initiative and National Symposium on Postsecondary Student Success, NPEC is funded by NCES, an agency of the U.S. Department of Education.

Gandolfo, A 1998, Brave new world? The challenge of technology to time-honored pedagogies and traditional structures, In Gillespie, KH (Ed.), The impact of technology on faculty development, life and work (pp. 23-38).

Higher Education Quality Committee, 2011.

Kouzes, JM \& Posner, BZ 1995, The leadership challenge, San Francisco: Jossey-Bass.

Land, R 2004, Educational development: Discourse, identity and practice, Berkshire, UK: Open University Press.

Alderson, M Wagener, U \& Shamanism N 2000, Teaching and learning in higher education, 1980-2000, Change Magazine, vol. 32 , no. 3, pp.13-19.

Luckett K 1995, Towards a model of curriculum development for the University of Natal 's curriculum reform programme, Academic development, vol. 1, no. 2, pp. 125-139.

Makondo, L 2014, Academics attraction and retention trends at a South African university, Journal of Sociology and Social Anthropology, vol.5, no. 2, pp. 169-177.

Makondo, L 2014, Academic advising in universities: Concept paper, Journal of Sociology and Social Anthropology, vol.5, no. 2, pp. 179186.

Makondo, L \& Makondo 0 2014, The interplay between South African Higher Education context and academic development, Anthropologist, vol. 17, no.2, pp.301-309.

Makondo, L 2012, Mindset change prerequisite for academic excellence: A case of four Zimbabwean and South African universities, South Africa Journal of Higher Education, vol. 26, no. 1, pp. 105-119.

Makondo, L. 2010, University students are being failed by the 'qualified': A cry from seven African universities, Practice and theory in systems of education, vol.5, no.3, pp. 263-276.

Mammon, K 2006, Academics' perception of 'quality in higher education and quality strategies', South African Journal of Higher Education, vol. 20, no. 5, pp. 639-643.

Maphosa, C \& Mudzielwana, NP 2014, Professionalization of teaching in universities: A compelling case, International Journal of Educational Sciences, vol.6, no. 1, pp.65-73.

Maphosa, C \& Wadesango, N 2014, Interrogating the role of academic developers in the promotion of scholarly teaching and scholarship of learning and teaching, International Journal of Educational Sciences, vol. 6, no. 1, pp.75-83.

Mercer, N 1995, The Guided Construction of Knowledge: talk amongst teachers and learners, Clevedon, Multilingual Matters Ltd.

Ndebele, C 2014, Approach towards the professional development of academics as espoused in institutional policy developments at a South African University, Journal of Social Sciences, vol. 38, no. 3, pp. 255-269.

Ndebele, C 2014, Deconstructing the narratives of educational developers on the enabling and constraining conditions in their growth, development and roles as educational staff development facilitators at a South African University, International Journal of Educational Sciences, vol. 6, no. 1, pp.103-115.

Northedge, A 2003, Enabling participation in academic discourse, Teaching in Higher Education, vol. 8.

O'Neill, G 2010, Initiating curriculum revision: Exploring the practices of educational developers, International journal for academic development. vol.15, 1, pp. 61-71.

Ornstein, AC \& Hunkins, FP 2009, Curriculum foundations, principles and issues, (5 $5^{\text {th }}$ ed.). Boston, MA: Allyn and Bacon.

Palmer, P 1998, The courage to teach, San Francisco: Jossey-Bass.

Starfield, S 1994, Multicultural Classrooms in Higher Education, English Quarterly, vol. 26, no. 3, pp.16 - 21.

Taylor, KL 2005, Academic Development as Institutional Leadership: An interplay of person, role, strategy, and institution, International Journal for Academic Development, vol. 10, no. 1, pp. 31-46.

Wells, G \& Claxton, G 2002, Learning For Life in the 21st Century: sociocultural perspectives on the future of education, Oxford: Blackwell. 
